\title{
THE EXTENT OF THE PANCREATIC LESIONS IN DIABETIC CHILDREN
}

\author{
BY
}

\author{
HENRY E. W. ROBERTON, M.A., M.B., B.Ch.
}

(From Addenbrookes Hospital, Cambridge, and St. Bartholomew's Hospital, London.)

Diabetes in children is usually a progressive disease. After each of the infections from which all children suffer, the insulin requirement becomes permanently higher, even if there is a slight remission during convalescence.

By analogy with nephritis and other progressive diseases, the pancreatic lesions might be expected to become worse until life is no longer possible. However, diabetic children can be kept healthy with insulin even if the disease is of long standing. It is possible, then, that the severe cases may have no power of secreting insulin, or so little as to be clinically negligible.

The patients quoted below were treated on low carbohydrate (e.g., ' Line and Ladder') diets.

On the whole, their insulin requirements are far above those of most of the diabetic adults treated at the same hospitals.

The C/I ratio. - I have devised a simple method of estimating the insulin-secreting power of the pancreas. It can be used for patients of any age and on any diet of the low carbohydrate type. Though not exact it can be applied to large numbers of cases from the literature or from hospital records. The variations in pancreatic efficiency are large compared with the errors due to the inaccuracies of the method.

The index of severity is the ratio of the potential carbohydrate of the diet to the insulin required to keep the urine sugar-free, in the absence of infections or toxæmia. It is referred to as the $\mathrm{C} / \mathrm{I}$ ratio.

It is suggested in this paper that when the $C / I$ ratio is between 1.5 and 2 the patient is secreting little, or perhaps no, insulin. It is shown that children tend in time to get the ratio 1.5 ; after this they remain constant.

The formula used to estimate the potential carbohydrate of the diet is $\mathrm{C}=0.6 \mathrm{P}$. This is an approximation of the formula ${ }^{1} \mathrm{C}=0.58 \mathrm{P}+0 \cdot 1 \mathrm{~F}$. For example,

$$
\begin{aligned}
& \text { If } \mathrm{C}=40, \mathrm{P}=75, \mathrm{~F}=100, \\
& \text { Potential } \mathrm{C}=40+0 \cdot 6 \text { of } 75,=85
\end{aligned}
$$


Limitations in the use of the $\mathrm{C} / \mathrm{I}$ ratio.-The diets must be of approximately the same type. If traces of sugar are found in the urine they may be neglected without appreciable error, as was found by sugar estimations on two patients. The insulin must be reduced as far as possible without causing glycosuria, as otherwise unduly low ratios are obtained. The patient must not be in a septic or toxic condition, or passing aceto-acetic acid in the urine.

The method is admittedly inexact, but the results are sufficiently constant to justify its use.

Estimations on cases in the literature.-In Toverud's series ${ }^{2}$ the children tend in time to require a constant 28 to 56 units, after 2 or 3 years.

As, unfortunately, only the insulin requirement is given, and not the diet, except in the case reports, the decreasing ratios cannot be demonstrated.

Some of the milder cases after 4 years still have a high ratio. The fact that the 3-year group has higher ratios than the later groups is difficult to explain. The most likely explanation is that the severe cases died early in the disease in the earlier years.

1923 series :-4 years duration, of 8,4 died (50 per cent.).

Ratios of the survivors, $1.3,1.3,1 \cdot 7,2.3$.

1924 series :-3 years duration, of 23,11 died ( 47 per cent.).

Ratios of the survivors, $1 \cdot 7,2 \cdot 1,2 \cdot 1,2 \cdot 2,2 \cdot 2,2 \cdot 8,2 \cdot 9,3 \cdot 1,3 \cdot 4$, $3 \cdot 5,4 \cdot 0,4 \cdot 7$.

1925 series:-Of 10, 2 died (20 per cent.).

Ratios of the survivors, $1 \cdot 0,1 \cdot 4,1 \cdot 7,1 \cdot 7,1 \cdot 9,2 \cdot 5,2 \cdot 7,3 \cdot 8$.

The figures were obtained in 1927. The diets were of the order of C.P.F. $=1.1 .2-3$.

Joslin $^{3}$ gives the food and insulin requirements in 1928 of 11 cases- of long duration. He only gives the diets of two in full, of the rest he gives the carbohydrate. $\mathrm{C} / \mathrm{I}$ ratios have been worked out on the assumption that the other diets were similar. The error is unlikely to be more than 10 per cent.

Duration of disease 9 years, C/I ratios 6.0, 3.4, 1.9 .

$\begin{array}{llllllll}, & , & 8 & , & , & , & 4, & 2 \cdot 5 . \\ , & , & 7 & , & , & , & 4, & 2 \cdot 8 . \\ , & , & 6 & , & , & , & 1 \cdot 9,1 \cdot 8,1 \cdot 7 . \\ , & \text { ", } & 5 & , & , & , & 2 \cdot 6 .\end{array}$

I have collected a series of cases from Addenbrookes Hospital, Cambridge, up to 1931 -

Duration of disease 8 years, C/I ratios $1 \cdot 6$.

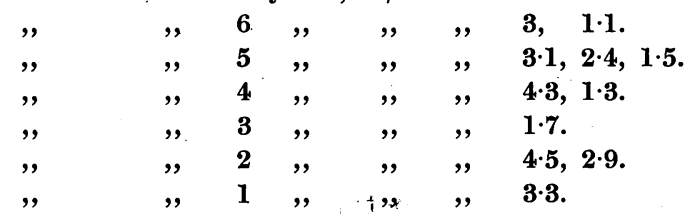

And a further series from St. Bartholomew's Hospital (up to 1931, unselected)- 


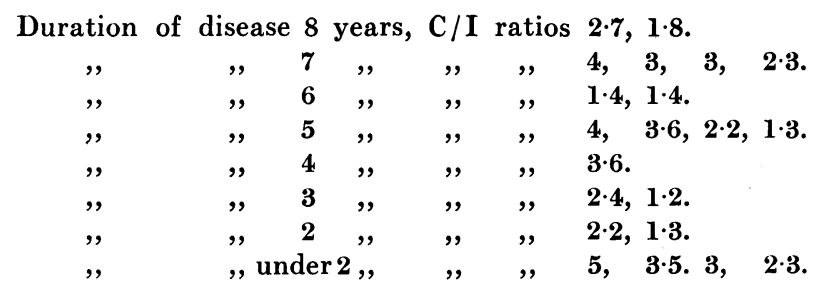

It is interesting to note that adults recovering from coma or ketosis frequently have a C/I ratio of about 1.5 for a few days. After this they return to their usual 3 or 4 . The coma may be largely due to the toxæmia temporarily putting the pancreatic secretion out of action. In the early stages of recovery, though the disease is controlled by insulin, the pancreas has not started to secrete properly. Such cases seldom have ratios below 1.5 after ketosis has been stopped.

I have not yet succeeded in finding more than one case whose ratio, when stabilized, is below 1. This case (Lawrence ${ }^{6}$ ) was not typical diabetes, and there were other factors than pancreatic deficiency.

The glucose equivalent of insulin.-Woodyatt ${ }^{4}$ found that the unit of insulin was equivalent to $1-1.5 \mathrm{grm}$. glucose. He put patients on an extremely low carbohydrate diet (on the verge of ketosis) with a great excess of fat, and estimated the daily output of sugar, which was considerable. With a constant diet the same patient passed 1-1.5 grm. less sugar for each unit of insulin.

Allen" found that in depancreatized dogs the unit was equivalent to 3-7: grm. sugar. They were on a high carbohydrate diet, about 100-150 grm., with 20-30 grm. protein, and no fat other than that contained in lean meat. He allowed for some of the protein being burned as carbohydrate. The dogs had a considerable glycosuria. The lower the output of sugar, the lower the sugar equivalent of insulin.

The patients described in my series are not strictly comparable to the diabetics and dogs mentioned above, as they were sugar free or nearly so, and were on diets between the low carbohydrate of Woodyatt's patients and the high carbohydrate and low fat of the dogs.

Had Allen's dogs and Woodyatt's humans been sugar free, the latter also always ketone free, the values would have been slightly different, probably a lower $\mathrm{C} / \mathrm{I}$ value.

Whereas I estimated my patients' total sugar and insulin, in these experiments only alterations of sugar in response to insulin were estimated. Calculations of the $\mathrm{C} / \mathrm{I}$ ratio on these patients were impossible on account of the gross glycosuria.

The unit of insulin appears to correspond to $1-1.5 \mathrm{grm}$. glucose on a low carbohydrate diet, and to 3-7 grm. on a high carbohydrate diet.

A total diabetic with a diet of the order of C.45, P.74, F.130 would therefore be expected to have a ratio between these extremes. When a patient is changed from a diet of this type to a diet of C.150, P.50, F.50, the $\mathrm{C} / \mathrm{I}$ ratio rises. 
The view that these children are total diabetics is therefore consistent with the results of these experiments.

Survey of the $\mathrm{C} / \mathrm{I}$ ratios of all the available children. - The tendency of the $\mathrm{C} / \mathrm{I}$ ratio to fall to $\mathbf{1 . 5}$ is shown in two charts.

Chart I. - The curve shows the number of children with a given ratio, in groups of 0.5. The greatest number of cases is in the group 1.5. There are few below this. There must be some factor preventing the pancreas from degenerating further. The cases are taken from St. Bartholomew's Hospital, Addenbrookes Hospital, Toverud, and Joslin.

CHART I.

C/ 1 RATio LAST RECORDED, OF 65 CHILDREN. INCIDENCE OF C/I RATIOS IN GROUPS OF ' 5 . NONE BELOW 1. MAXimUm at $1 \cdot 5$.

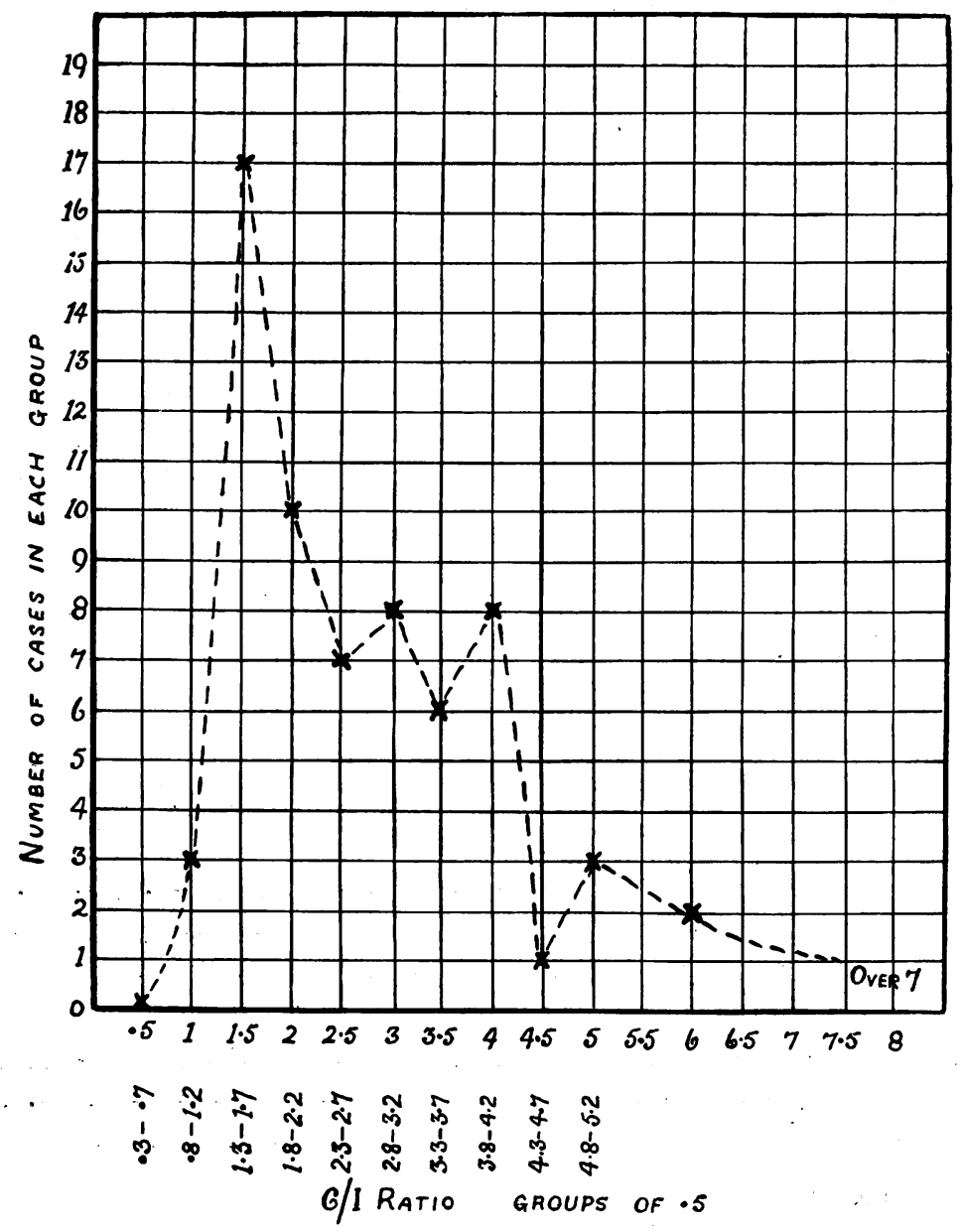


Chart II.-The chart shows that a few cases remain mild. The C/I ratio is plotted against the time since diabetes was diagnosed.

CHART II.

Chart of C/I ratios and duration.

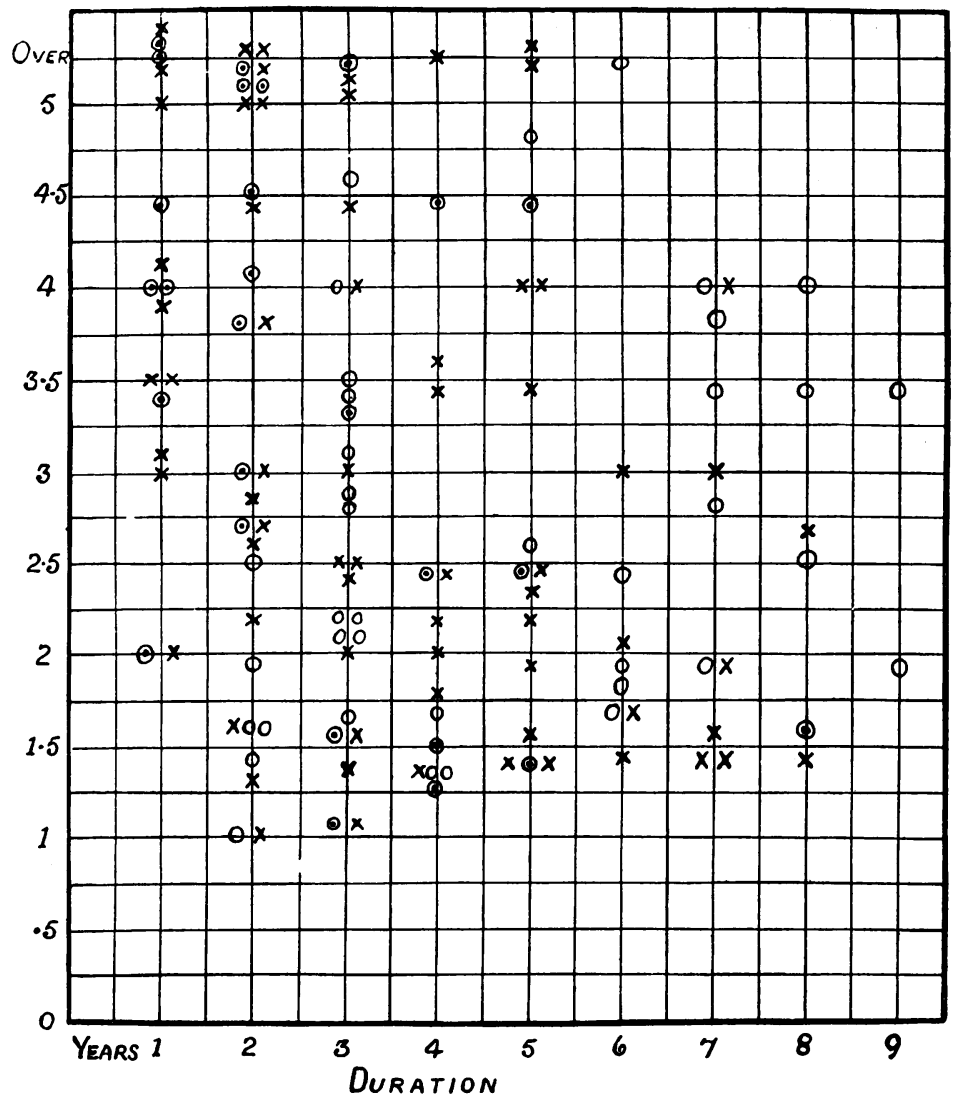

$X=S t$. Bartholomews O=ADDEn broOkes O-TOVERUd \& JosLIN

Summary.

During the last few years children with diabetes have tended to require progressively more insulin until they require 1 unit for each $1.5 \mathrm{grm}$. of potential carbohydrate in the diet. It is suggested that at this stage they are not secreting an appreciable amount of insulin, because (a) experiments show that 1 unit corresponds to about $1.5 \mathrm{grm}$. of glucose; and (b) exhaustion of the pancreas is the simplest explanation of the disease ceasing to be progressive at this stage.

My thanks are due to Dr. George Graham and the physicians of Addenbrookes Hospital for permission to use their cases and clinical records. 


\section{REFERENCES.}

1. Woodyatt, R. T., Arch. Int. Med., Chicago, 1921, XXVIII, 125.

2. Toverud, K. U., Brit. J. Child. Dis., Lond., 1927, XXIV, 258.

3. Joslin, E. P., Treatment of Diabetes Mell., Philad., 1928, 4th Ed.

4. Woodyatt, R. T., J. Metab. Res., N.J., 1922, II, 795.

5. Allen, F. M., Am. J. Physiol., Baltimore, 1924, LXVII, 275.

6. Lawrence, R. D., Quart. J. Med., Oxford, 1928, XXI, 359. 